\title{
Aspirin inhibits the proliferation and migration of gastric cancer cells in p53-knockout mice
}

\author{
XUE-FU LI, BING-ZHONG XU and SHI-ZHEN WANG \\ Department of Anatomy, Jiangsu Vocational College of Nursing, Huaian, Jiangsu 223300, P.R. China
}

Received January 29, 2016; Accepted August 18, 2016

DOI: $10.3892 / \mathrm{ol} .2016 .5067$

\begin{abstract}
The aim of the present study was to investigate the effect of aspirin on the cell proliferation and migration of gastric cancer cells in p53-knockout mice. Twenty p53 ${ }^{-/-}$male mice aged 6 to 7 weeks, with an average weight of $20 \pm 3 \mathrm{~g}$ were used. The model of gastric cancer was established by the implantation of a mouse forestomach carcinoma cell line, subcutaneously, at the back of the neck, and then the mice were randomly divided into two groups after establishment of the model (control group, $n=10$; experimental group, $n=10$ ). Aspirin $(250 \mathrm{mg} / \mathrm{kg}$ ) was added to the food in the experimental group one day before model establishment, until the end of the experiment. Mice in the control group were given regular food without aspirin. All mice were sacrificed 3 months afterwards, and gastric cancer tissues were harvested. MTT assay was used to detect the proliferation of the tumor cells. Tumor cell number was also observed. Migration ability was detected by scratch assay, and E-cadherin protein expression was evaluated by immunofluorescence. The results revealed that the proliferation ability of tumor cells in the experimental group was lower than that in the control group. In addition, cell numbers were significantly decreased and the migration ability was diminished. The expression of E-cadherin was also increased in the experimental group, and the differences were statistically significant $(\mathrm{P}<0.05)$. In conclusion, aspirin inhibited the cell proliferation and migration of gastric cancer cells in mice.
\end{abstract}

\section{Introduction}

Aspirin is a very commonly used clinical drug with antipyretic, analgesic and antiplatelet functions (1). Recently, animal studies and clinical observations $(2,3)$ have found that regular doses of aspirin play a role in the prevention and treatment of

Correspondence to: Xue-Fu Li, Department of Anatomy, Jiangsu Vocational College of Nursing, 2 Huanghe Road, Huaian, Jiangsu 223300, P.R. China

E-mail:1i_xuefu1@163.com

Key words: aspirin, p53 gene knockout, mice model of gastric cancer, cell proliferation and migration, E-cadherin protein colitis-associated colorectal cancer, and could reduce mortality in patients with liver metastasis. In addition, aspirin was found to have an inhibitory effect on the growth of esophageal cancer, ovarian cancer, liver cancer, breast cancer, lung cancer, lymphoma and endometrial cancer (4-6). However, the specific mechanism of action remains to be further explored. The present study analyzed whether aspirin also has an inhibitory effect on gastric cancer proliferation in p53 gene-knockout $\left(\mathrm{p} 53^{-/}\right.$) mouse with gastric cancer to provide a basis for its use in clinical treatment.

\section{Materials and methods}

Animals. Twenty p53/- male mice aged 6 to 7 weeks were used in the study. The average weight was $20 \pm 3 \mathrm{~g}$. Mice were purchased from Shanghai BangYao Biological Technology Co., Ltd. (Shanghai, China). Mice were given food and drinking water ad libitum and maintained at a constant temperature of $22 \pm 0.5^{\circ} \mathrm{C}$ with a 12 -h light/dark cycle (license no., SYXK< Shanghai >2015-0032).

Reagents and instruments. Mouse forestomach carcinoma cell line (MFC) was purchased from the Cell Bank of the Chinese Academy of Sciences (Shanghai); aspirin was purchased from Sigma (St. Louis, MO, USA). RPMI-1640 medium (containing $15 \%$ fetal bovine serum, $100 \mu / \mathrm{ml}$ penicillin and $100 \mu / \mathrm{ml}$ streptomycin) were obtained from HyClone (Logan, UT, USA). Trypsin was obtained from Gibco (Grand Island, NY, USA). PBS was purchased from Shanghai Biological Engineering Company (Shanghai, China). MTT assay $(5 \mathrm{mg} / \mathrm{ml})$ was obtained from Sigma (St. Louis, MO, USA). Polyclonal rabbit anti-human E-cadherin was purchased from Santa Cruz Biotechnology, Inc. (Santa Cruz, CA, USA). FITC-labeled goat anti-rabbit IgG was from Beijing Zhong Shan Jinqiao Biological Technology Co., Ltd. (Beijing, China). Centrifuge was obtained from Thermo Fisher Scientific (Waltham, MA, USA) and syringes were from Bio-Rad (Berkeley, CA, USA). Inverted microscope was from Olympus (Tokyo Japan), Eppendorf tubes were obtained from Eppendorf (Hauppauge, NY, USA), super clean bench was from Thermo Fisher Scientific (Waltham, MA, USA), and cell counting chamber was from Shanghai Optical Instrument Factory (Shanghai, China). Paraffin slicing machine and tissue embedder were obtained from Leica (Mannheim, Germany) and ELISA plate reader was from Bio-Rad. 
Establishment of a mouse model of gastric cancer. MFC cells were cultured in RPMI-1640 medium and placed in the incubator with saturated humidity and $5 \% \mathrm{CO}_{2}$ at $37^{\circ} \mathrm{C}$, and passaged every 3 or 4 days. MCF cells in the logarithmic growth phase were trypsinized with $1 \mathrm{ml}$ of $0.25 \%$ trypsin and observed under an inverted microscope. When the adherent cells gradually became round, $3 \mathrm{ml}$ of medium was used to terminate the digestion. Culture flasks were agitated left and right, gently to make the cells detach from the bottom of the bottle. The cell suspension was then transferred into a centrifuge tube for centrifugation at 1,000 rpm for $5 \mathrm{~min}$. The supernatant was discarded and PBS was added to resuspend the cells. A cell counting plate was used for counting, and the cell concentration was adjusted to $1.0 \times 10^{7} / \mathrm{ml}$.

After skin disinfection at the back of the neck of the mice, $1 \mathrm{ml}$ syringes were used to aspirate MFC cell suspensions, and were then inserted into the skin at an angle of roughly 30 degrees, withdrawing without liquid, and then the cells were injected. Each mouse was injected with $0.2 \mathrm{ml}$ of cell suspension. After inoculation, the mice were fed with normal diet and water.

After successful establishment of the cancer model, mice were randomly divided into a control group $(n=10)$ and an experimental group $(n=10)$. Mice in the experimental group were treated with aspirin at the dose of $250 \mathrm{mg} / \mathrm{kg}$ daily one day before cancer model establishment, until the end of the experiment; the control group was fed without aspirin. Ten $\mathrm{p} 53^{-/}$male mice were chosen as the control group, and given regular food. Three months later, all mice were sacrificed to harvest gastric cancer tissues. MTT assay was used to detect cell proliferation. The Gonzalez-Garcia method was used to detect the number of tumor cells (7). Scratch assay was adopted to measure the migration ability. Immunofluorescence microscopy was used to detect the expression of E-cadherin protein.

MTT assay. Cells were collected in the logarithmic growth phase and seeded in wells of a 96-well culture plate at a density of $5 \times 10^{3}$ cells/well in RPMI-1640 medium containing $10 \%$ fetal bovine serum. Cells were allowed to incubate for $24 \mathrm{~h}$ and then the supernatant was removed. Twenty microliters of MTT reagent was added to the wells every $24 \mathrm{~h}$ and each time point was analyzed in triplicate. After continuous monitoring for 6 days and cultivation for $4 \mathrm{~h}$ in the incubator, the supernatant was completely removed. Then dimethyl sulfoxide (DMSO) was added to each well and placed on a shaker for 10 min until the purple crystals fully dissolved. Finally, the absorbance value (A490) at a wavelength of $570 \mathrm{~nm}$ was measured using an ELISA plate reader.

Cell scratch assay. A marker was used to draw lines across the back of culture plates. Cells $\left(5 \times 10^{5}\right)$ were added to each plate of the corresponding experimental groups. Sterile pipette tips $(200 \mu \mathrm{l})$ were used to make a scratch in the cell monolayer across the bottom of the well. Cells were then allowed to grow in Dulbecco's modified Eagle's medium (DMEM) containing $5 \%$ calf serum. The cell migration in the wounded area was observed.

Immunofluorescence assay. Sterile coverslips were placed in 6 -well plates. Cell suspension in the logarithmic growth phase

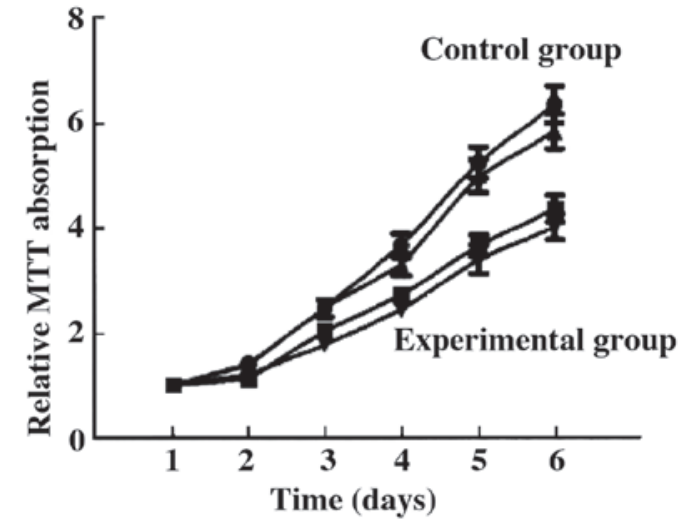

Figure 1. Proliferation ability of the tumor cells by MTT assay.

was inoculated into each well and allowed to grow under conventional conditions and grown to an appropriate density. Cells were washed 3 times with PBS, fixed for 20 min with prechilled pure acetone and then washed with PBS again 3 times. The serum of normal non-immune animals was used to block the cells for $10 \mathrm{~min}$. The cells were washed 3 times with PBS, and rabbit anti-human E-cadherin polyclonal antibody and mouse anti-human $\beta$-catenin monoclonal antibody (1:200) were added respectively, and left to incubate at $4^{\circ} \mathrm{C}$ overnight. Cells were next washed with PBS 3 times for $10 \mathrm{~min}$. FITClabeled goat anti-rabbit $\operatorname{IgG}(1: 80)$ was added and incubation was carried out for $60 \mathrm{~min}$ at room temperature. Cells were washed 3 times with PBS and $5 \mu \mathrm{g} / \mathrm{ml}$ of propidium iodide (PI) was used to counterstain nuclei for $30 \mathrm{~min}$. The cells were washed with distilled water 3 times, and coverslips were mounted with buffered glycerol (PBS:glycerol, 1:9). Slides were observed and images were captured under a fluorescence microscope $(\mathrm{x} 400)$ as soon as possible. PBS was replaced with the primary antibody as a blank control.

Statistical analysis. SPSS 19.0 was used to make statistical analyses. Data are presented as the mean \pm SD. Statistical significance between the two groups was analyzed using t-test. The counting data were presented as cases or percentage, while $\chi^{2}$ test was used for comparison among groups. $\mathrm{P}<0.05$ was considered to indicate a statistically significant difference.

\section{Results}

Cell proliferation. Compared with the control group, the proliferation ability of the tumor cells in the experimental group was significantly decreased. The number of cells was significantly decreased compared to the control group $(6.34 \pm 1.05$ vs. $3.42 \pm 1.12, \mathrm{t}=5.624, \mathrm{P}=0.027)(\mathrm{P}<0.05)($ Fig. 1$)$.

Cell migration. The tumor cell migration ability of the experimental group was decreased, and the expression levels of E-cadherin were increased. The differences were statistically significant $(\mathrm{P}<0.05)$ (Figs. 2 and 3).

\section{Discussion}

Gastric cancer is a common digestive tract cancer with the fourth leading incidence rate and the second highest mortality 
o h

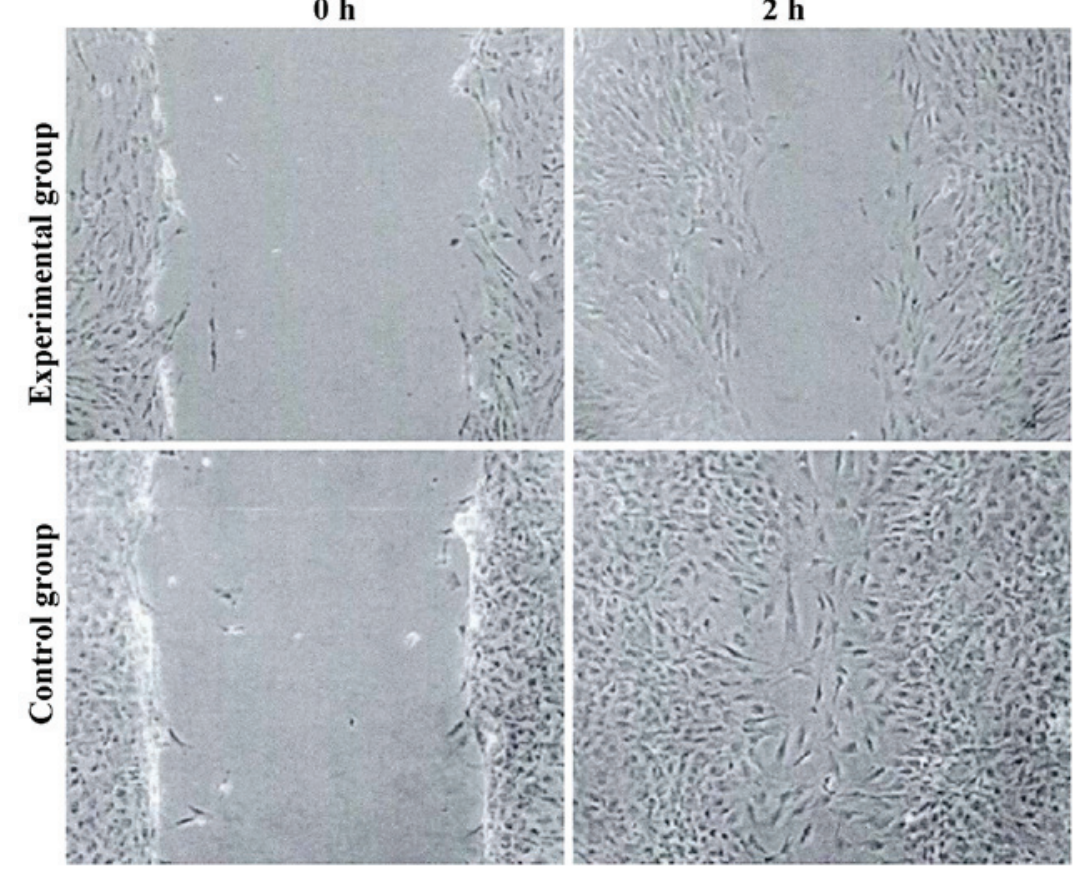

Figure 2 . The migration of tumor cells by cell scratch assay.
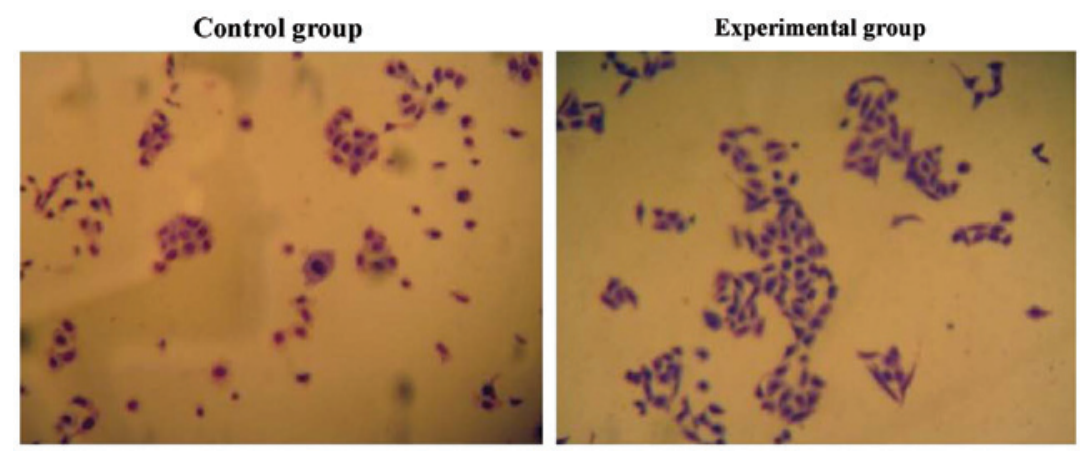

Figure 3. The expression of E-cadherin by immunofluorescence. rate in the world (8). The pathogenesis of gastric cancer is not yet fully understood. Surgical resection is still the main method of treatment. The average 5-year survival rate following surgery is $\leq 30 \%$. Invasion and metastasis are the main causes of death in patients with gastric cancer (9).

Animal models of gastric cancer include (10): i) use of the carcinogen, N-methyl-N'-nitro-N-nitrosoguanidine (MNNG); ii) use of Helicobacter pylori (HP) infection to induce gastric carcinoma, or combined MNNG carcinogen with HP; iii) immunodeficient animals transplanted with gastric cancer cells; and iv) transgenic methods using genes that regulate the formation of gastric cancer transfected into animal embryos to form tumors. This study used $\mathrm{p} 53^{-/-}$mice to establish a mouse model of gastric cancer through subcutaneous seeding of MFC cells. On the one hand, $\mathrm{p} 53^{-/-}$mice had steady strain and the tumorigenesis rate was high (11); in addition, the high mortality rate when using carcinogens was lower (10). Previous research showed that subcutaneous seeding of MFC cells to establish a model of gastric cancer had a short cycle, of roughly 10 days, and the success rate was as high as $95 \%$ (12).
Mice receiving aspirin (250 $\mathrm{mg} / \mathrm{kg} / \mathrm{day})$ is equivalent to the conventional oral dosage of $100 \mathrm{mg} /$ day for adults. ukCAP, a randomized double blind trial of aspirin in the UK, which aimed to prevent the formation of colonic tumors, reported that a daily dose of $300 \mathrm{mg}$ of aspirin, supplemented with folic acid, reduced the risk of adenomas and advanced adenomas by approximately 21 and $37 \%$ respectively when compared to the placebo group after 3 years (13). The mechanism by which aspirin inhibits tumor growth and migration may involve reduction in the expression level of $\mathrm{COX}-2$, and the production of prostaglandins (PGs) $(14,15)$. COX-2, often overexpressed in tumor tissues, can promote inflammation and cell proliferation. Oshima found that the number of polyps in the colon and small intestine decreased significantly after COX-2 gene knockout in adenomatous polyposis coli (APC) gene knockout mouse models (16). PGE2 can inhibit the production of lymphatic factors that have immune modulating function and can also inhibit the proliferation of T cells and B cells (17). In addition, some studies have indicated that aspirin can inhibit Bcl-2 activity, increase Bax expression and inhibit the activity of $\mathrm{NF}-\kappa \mathrm{B}$ (18). 
Tumor metastasis is a complex biological process which is regulated by different genes and molecular pathways. At present, it is believed that tumor metastasis mainly includes the following steps: i) separation from primary lesions, in which cells undergo epithelial-to-mesenchymal transition (EMT) in order to detach; ii) cell invasion of surrounding tissues, in which cells penetrate the basement membrane and reach blood vessels or lymphatics, a process mediated by matrix metalloproteinases (MMPs) and proteolytic enzymes; iii) survival in the vasculature or lymphatic system; and iv) migration from the blood or lymph vessels, adhesion in distal tissues, and formation of micrometastatic nodes (19). Epithelial cells express E-cadherin to achieve intercellular adhesion, the expression of E-cadherin protein is increased, while the occurrence of EMT is decreased (20). This study has shown that the proliferation ability of tumor cells in the experimental group was weakened and the number of cells and migration ability were also decreased.

In conclusion, aspirin can inhibit the proliferation and migration of gastric tumor cells in mice.

\section{Acknowledgements}

This study was supported by the Science and Technology Project of Huaian, Jiangsu Province (project no. HAS2013029).

\section{References}

1. Soon S, Chia WJ, Redekop K and Wee HL: A cost-effectiveness analysis of aspirin in the primary prevention of cardiovascular diseases and colorectal cancer. Value Health 18: A462, 2015.

2. Wilson LF, Green AC, Kendall BJ, Jordan SJ, Nagle CM, Bain CJ, Neale RE and Whiteman DC: Cancers prevented in Australia in 2010 through the consumption of aspirin. Aust NZ J Public Health 39: 414-417, 2015.

3. Wright JL, Chéry L, Holt S, Lin DW, Luedeke M, Rinckleb AE, Maier C and Stanford JL: Aspirin and NSAID use in association with molecular subtypes of prostate cancer defined by TMPRSS2: ERG fusion status. Prostate Cancer Prostatic Dis 19: 53-56, 2015.

4. Mikami J, Kurokawa Y, Takahashi T, Miyazaki Y, Yamasaki M, Miyata H, Nakajima K, Takiguchi S, Mori M and Doki Y: Antitumor effect of antiplatelet agents in gastric cancer cells: an in vivo and in vitro study. Gastric Cancer, Oct 202015 (Epub ahead of print).

5. Zhang YP, Wan YD, Sun YL, Li J and Zhu RT: Aspirin might reduce the incidence of pancreatic cancer: a meta-analysis of observational studies. Sci Rep 5: 15460, 2015.

6. Wan L, Dong H, Xu H, Ma J, Zhu Y, Lu Y, Wang J, Zhang T, Li T, Xie J, et al: Aspirin, lysine, mifepristone and doxycycline combined can effectively and safely prevent and treat cancer metastasis: prevent seeds from gemmating on soil. Oncotarget 6: 35157-35172, 2015.
7. Gonzalez-Gonzalez M, Garcia J, Alcazar JA, Gutierrez ML, Gonzalez LM, Bengoechea O, Abad MM, Santos-Briz A, Blanco O, Martin M, Rodriguez A, Fuentes M, Munoz-Bellvis L, Orfao A and Sayagues JM: Association between the cytogenetic profile of tumor cells and response to preoperative radiochemotherapy in locally advanced rectal cancer. Medicine (Baltimore) 93: e153, 2014.

8. Fontana E, Smyth EC, Cunningham D, Rao S, Watkins D, Allum WH, Thompson J, Waddell T, Peckitt C, Chau I, et al: Improved survival in resected oesophageal and gastric adenocarcinomas over a decade: the Royal Marsden experience 2001-2010. Gastric Cancer, Nov 5, 2015 (Epub ahead of print).

9. Gu Q, Zhang J, Hu H, Tan YE, Shi S and Nian Y: Clinical significance of MiR-137 expression in patients with gastric cancer after radical gastrectomy. PLos One 10: e0142377, 2015.

10. Sugimura T and Fujimura S: Tumour production in glandular stomach of rat by $\mathrm{N}$-methyl-N'-nitro-N-nitrosoguanidine. Nature 216: 943-944, 1967.

11. Thompson J, Epting T, Schwarzkopf G, Singhofen A, Eades-Perner AM, van Der Putten $\mathrm{H}$ and Zimmermann W: A transgenic mouse line that develops early-onset invasive gastric carcinoma provides a model for carcinoembryonic antigen-targeted tumor therapy. Int J Cancer 86: 863-869, 2000.

12. Furukawa $H$, Iwanaga $T$, Nakajima T, Okabayashi K, Nakazato $H$, Hiratsuka M, Ohta K, Kito T, Yamamura Y and Goto S: Randomized study with mitomycin $\mathrm{C}+5$-fluorouracil+cytosine arabinoside (MFC)+5-fluorouracil, MFC+tegafur and uracil (UFT), and MF+UFT in advanced gastric cancer: interinstitutional differences in a multicenter study in Japan. J Surg Oncol 60: 59-64, 1995.

13. Logan RF, Grainge MJ, Shepherd VC, Armitage NC and Muir KR; ukCAP Trial Group: Aspirin and folic acid for the prevention of recurrent colorectal adenomas. Gastroenterology 134: 29-38, 2008.

14. Osborn VW, Chen SC, Weiner J, Schwartz D and Schreiber D: Impact of aspirin on clinical outcomes for African American men with prostate cancer undergoing radiation. Tumori 102: 65-70, 2015.

15. Huang WK, Tu HT and See LC. Aspirin use on incidence and mortality of gastrointestinal cancers: current state of epidemiological evidence. Curr Pharm Des 21: 5108-5115, 2015.

16. Di Francesco L, López Contreras LA, Sacco A and Patrignani P: New insights into the mechanism of action of aspirin in the prevention of colorectal neoplasia. Curr Pharm Des 21: 5116-5126, 2015.

17. Kraus S, Sion D and Arber N: Can we select patients for colorectal cancer prevention with aspirin? Curr Pharm Des 21: 5127-5134, 2015.

18. Kastrati I, Litosh VA, Zhao S, Alvarez M, Thatcher GR and Frasor J: A novel aspirin prodrug inhibits NFKB activity and breast cancer stem cell properties. BMC Cancer 15: 845, 2015.

19. Cheng GZ, Zhang W and Wang LH: Regulation of cancer cell survival, migration, and invasion by Twist: AKT2 comes to interplay. Cancer Res 68: 957-960, 2008.

20. Qin Y, Tang B, Hu CJ, Xiao YF, Xie R, Yong X, Wu YY, Dong H and Yang SM: An hTERT/ZEB1 complex directly regulates E-cadherin to promote epithelial-to-mesenchymal transition (EMT) in colorectal cancer. Oncotarget 7: 351-361, 2016. 